\title{
Sustainable development management: analysis of interaction of social institutions (on the example of the Republic of Tatarstan)
}

\author{
Alisa Shakirova ${ }^{1,{ }^{*}}$, Lyudmila Gudyaeva ${ }^{1}$, and Mariia Prygunova ${ }^{1,2}$ \\ ${ }^{1}$ Center for Advanced Economic Research, Academy of Sciences of the Republic of Tatarstan, 23/6 \\ Karl Marks str., 420111, Kazan, Russian Federation \\ ${ }^{2}$ Kazan Federal University, 8 Kremlevskaya str., 420111, Kazan, Russian Federation
}

\begin{abstract}
This work focuses on the changes that occur in the geopolitical and economic systems and directly affect the functioning of the institution of social protection of the population. The purpose of this article is to analyze the impact of state management processes on the institution of social protection of the population in terms of statistics. With the help of a secondary analysis of sociological research, federal and regional regulatory framework, statistical indicators of the 2012-2018 period, the author considers social phenomena that cause the transition to sustainable development. Researchers study the assessment of the impact of social institutions in detail, among them: economics, politics, international activities, health care, religion, education for the society in the context of modern trends and prospects for sustainable economic development. The article examines the economic and geopolitical crises and their impact on the sphere of social protection of the population. The analysis made it possible to conclude that the political institution determines the vector of development of social protection of the country as a whole, and the institution of religion locally provides assistance to certain segments of the population. The close relationship of the field of health and education with each other is shown, as well as the relationship with other social spheres, in order to ensure sustainable development of the territories.
\end{abstract}

\section{Introduction}

The solution of socially significant issues lying in the field of intersection of different spheres of life requires close cooperation with the specialists from a wide range of scientific knowledge in the field of health care, religious studies and others. Below we will consider the interaction of the institution of social protection of the population with other institutions in more detail. The main task of social protection of the population is the implementation and improvement of state policy and public administration in the field of improving the level and quality of life, well-being of the population. Various factors influence the institution of social protection of the population and the social policy of the country as a

${ }^{*}$ Corresponding author:Alisa.shakirova@tatar.ru 
whole. Quantitatively and qualitatively, these factors are extremely numerous, diverse and multidirectional. Their combinations are even more varied, which determines the greater complexity of their classification. Factors such as the state of the economy, the political situation, scientific and technological progress, sociocultural and international events have an indirect impact, that is, they have a certain potential for impact, without exerting it directly and immediately. In this article, the authors, using the secondary analysis method, reveal the interaction and influence of state processes on the functioning of the institution of social protection of the population.

\section{Materials and methods}

The article presents the results of a secondary analysis of the following studies: "Economic crisis and consumption" (2014-2015, Levada Center) and "Indices of social well-being" (2014-2015, Russian Public Opinion Research Center). The scientific work considers the legislative and regulatory acts of the Government of the Russian Federation and the Republic of Tatarstan, materials of statistical collections of the Federal State Statistics Service of 2012-2018, data of the Ministry of Labor and Social Protection of the Russian Federation, the annual report of the Ministry of Labor, Employment and Social Protection of the Republic of Tatarstan for 2012-2018.

\section{Results and Discussion}

The state, as a political institution, is responsible for the safety of a society. The state performs various internal functions, such as regulating the economy, maintaining the stability of the society, ensuring the social harmony, ensuring the protection of the population, and many others. Let us consider in more detail how the state influences the functioning of the institution of social protection of the population. The institution of politics is determined by various trends, including the sociocultural ones.

Interest groups and public, volunteer, charitable organizations are also an element of the political institution. It is these social agents that can influence the political sphere in which social service issues are raised. For example, in the subject of Russia - the Republic of Tatarstan (hereinafter - RT), the problem of disabled people attracted the attention of such a social agent as the All-Russian Society of Disabled People, contributed to the adoption of various kinds of legislative acts:

1) long-term target program of the Republic of Tatarstan "Accessible Environment" for 2011-2015;

2) Resolution of the Cabinet of Ministers of the Republic of Tatarstan dated September 28, 2015 No. 716 "On approval of the Action Plan ("road map") to increase the values of indicators of accessibility of facilities and services for disabled people in the Republic of Tatarstan for 2015 - 2030"; and etc.

Globalization, development of the scientific field and the emergence of new technologies have led to the information revolution. There is an opportunity to exchange information between the regions, countries and international organizations, the leaders of the states. This, in turn, determines the emergence of not only the norms of international law themselves, but also the emergence of an international institution. The institution of social protection of the population also does not stand aside, and actively interacts with international organizations and institutions, which in turn leads to improvement, changes in 
the institution of social protection and its parts. For example, consider how international relations affect the institution of social protection of the population. First of all, we will describe sports events such as 2013 Universiade, 2015 World Aquatics Championships and 2018 FIFA World Cup, the 45th World Skills World Championship of 2019. First of all, these events have a huge legacy. This includes, for example, the construction of KazanArena sports facilities, a water sports palace and other facilities that meet international standards and requirements, including the requirement to provide a barrier-free environment, thanks to which the sports infrastructure is gradually becoming accessible to people with disabilities. So, from 2010 to 2013, an increase in the number of equipped sports facilities can be observed, which was previously not at all a priority in sports policy, and today many sports facilities are adapted for sports for people with disabilities $[1,47]$. If in 2011 the share of disabled people involved in sports was $4.25 \%$, then by 2013 their share had grown to $6.9 \%$, and by 2018 - already up to $18.3 \%$ [2]. Thus, after the international events, the quality of life of people with disabilities has reached a new level.

The well-being of the country's population is primarily based on a balanced sustainable economy. Thanks to the social protection of the population, it becomes possible to smooth out a social injustice. The interrelation of economic and social protection institutions is especially noticeable during the economic crises. For example, the economic crisis leads to the introduction of additional measures to support the population on the part of the state. In this regard, we will analyze the main indicators of the socio-economic development of the Republic of Tatarstan and study their impact on the organization of social protection of the population during the economic crisis in 2015 [3, p.18]

One of the main negative events in 2015 was the decline in real incomes of the population $(-4.0 \%)$, the beginning of which, due to the growth of inflation, can be observed already in $2014(-0.7 \%)$ [3, p. 17]. The average salary in the Russian Federation in 2014 amounted to 33,925 rubles, in the Republic of Tatarstan - 29,337.6 rubles. By 2015, the average wage in the republic decreased by $6.3 \%$ compared to the previous year, and in the country - by $9.5 \%$, while the real disposable income of the population decreased by $4.8 \%$ and $4 \%$ respectively.

The decline in wages of the population affected all sectors of the economy and also affected other components of disposable income as a result of the excess of the inflation rate, which overlapped their indexing. By the end of the year, the real amount of assigned pensions decreased by $4.8 \%$, which has not happened since 2009 . The situation is charged due to the growth of the consumer price index in 2014-2015.

The aggravation of negative trends is also observed according to the results of the Russian Public Opinion Research Center poll on January 31 - February 1, 2015 [4]. Thus, the life satisfaction index continues to decline and is 59 points in 2015 (against 65 points in February 2014 and 62 points in February 2013). The Russians also expressed their dissatisfaction with the material situation. So the indicator decreased by 7 points and amounted to 64 (against 73 points in February 2014 and 66 points in February 2013). One third (30\%) of the Russians surveyed began to accumulate funds in case of dismissal, for example, these figures in 2009 amounted to $21 \%$, in $2008-15 \%$.

The result of the decrease in the population's income, the rise in prices for goods and services, was the increasing stratification of the society. In 2014, we can observe a sharp jump in the increase in the number of the poor population in the Russian Federation, which remains in 2015 (2013 - 15.5; 2014 - 18.2; 2015 - 21 million people).

The number of poor population amounted to 22.9 million people, exceeding the value of this indicator in the crisis year of 2009, and these figures were achieved only in the first 
quarter of 2015. The measures taken by the state policy to smooth out inequality among the population did not pass without results, and the number of the poor decreased, although the value of the indicator remained at a high level.

In February 2015, the experts of the Levada Center company assessed the opinion of the population and revealed the deterioration of the country's economic situation in the views of the absolute majority of Russians (70\%). For example, a quarter of respondents $(24 \%)$ reported about the dismissal of their relatives. At the same time, the majority $(68 \%)$ of Russians did not have any cases of losing their jobs among their friends and relatives. Exactly half $(50 \%)$ of respondents believe that the layoff will not occur, but expect it (regarding their work or in relation to their relatives) with some degree of probability $38 \%$ of Russians (including 7\% are convinced of this or observe similar circumstances) [5].

A decrease in the real income of the population, an increase in the number of poor citizens, an increase in the number of unemployed have had a tremendous impact on the organization of social protection of the population. Firstly, there is a sharp need for additional measures to support the population, and secondly, the number of citizens who have the right to already existing social support measures has increased. The current situation led to an increase in the number of applications from the consumers of the social services to the organization of social protection, which by that time were not ready to receive a large number of citizens. The lack of the experts led to long queues and a corresponding increase in the level of dissatisfaction of the population with social protection organizations.

The analysis shows that the economic institution has a direct impact on the activities of social protection organizations. The regions, adapting to the conditions of the economic crisis, began to gradually reduce the social obligations to the population. The main action strategies include: suspension of indexation of payments, introduction of targeting mechanisms, reduction of social support, cancellation of some support measures, expansion or adoption of new support measures for certain categories of citizens.

Another important institution that influences the social support of the population is the institution of religion. For a long time, religion has performed the functions of protecting the weak, the disadvantaged and the sick ones, it lays the principles of love, beauty and mercy in people. Over time, social protection took over these functions. However, even today, religion interacts with state and municipal bodies, public organizations and individuals on issues of social protection of the population [6, p. 105].

At present, a synodal department is functioning at the Russian Orthodox Church (hereinafter - the ROC). This department is responsible for the charitable work of the church, as well as for the work of social service. It should be noted that a great responsibility and hope are laid on the church, because there are 2-5 charitable canteens for needy citizens in each diocese. Churches and chapels function in medical institutions, sisterhoods and various Orthodox medical societies have been created. Church ministers also work with drug addicts and alcoholics, work in orphanages and correctional camps. For example, all correctional camps and pre-trial detention centers, prisons have church premises, and in most of them (75\%) there are church communities [7. p. 87].

With the development of healthcare, there are more chances to prevent the onset and exacerbation of socially significant diseases, which reduces the level of disability and the subsequent burden on social protection organizations [8]. And vice versa, it is in the organization of social protection that citizens apply after getting the diagnoses and having obtained the "disabled" category . As part of this approach to maintaining health, the role of social work in the health care system is significantly increasing. Institutes of health care and 
social protection interact in solving common problems of citizens and improve the quality of life of the population. Thus, medical and social work is the achievement of the highest possible level of health, functioning and adaptation of persons with physical and mental pathologies, as well as with social troubles [9. p. 33].

There are several areas where the institutions of health care and social protection interact: the fields of psychiatry, narcology, oncology, family planning. Social work in the provision of palliative care is of particular importance, since this area has just begun to develop in Russia. D. M. da Silva, C. V. Dendask and E. de Oliveira conducted a bibliographic study of the experience of interaction of social work experts with cancer patients in 2010-2015 and came to the conclusion that the inclusion of social work in the overall process of patient care allows improve the quality of life of cancer patients [10]. Changes in the behavior of the patient and his relatives, in addition to the disease itself, causes the patient's attitude towards him, which in most cases requires correction and intervention from the outside. By engaging in the process of providing care, social protection organizations make a fundamental contribution to cooperation to improve the patient's life.

The institute of education also turns out to be closely related to social protection of the population. One of the topical areas of interaction between the educational institutions and social protection of the population is inclusive education of children with the disabilities. For the full inclusion of children with disabilities in the learning process at any stage (preschool, secondary, higher education), joint colossal efforts of these two institutions are required. So, for example, O.S. Stepanova and A.A. Nikolaeva analyzed the current problems of inclusive education in Russia [11]. According to the results of a sociological survey conducted by the researchers, more than thirty similar problems have been identified. The most acute of them: the problem of relations between ordinary students and children with disabilities; the problem of the financial capabilities of schools to create an accessible environment in order to form inclusive education, etc.

\section{Conclusion}

So, we can say that the influence of various institutions on the organization of social protection of the population manifests itself in different ways. Nevertheless, the general mechanism of influence is obvious: social agents draw attention to socially significant problems of the population, which leads to increased activity on the part of the state in solving these problems.

Foreign policy contributes not only to the exchange of experience between the countries, but also leaves its own legacy. For example, thanks to the holding of international sports competitions, the population, including people with disabilities, have the opportunity to go in for sports.

The unstable economic situation of the country has a negative impact on the activities of the institution of social protection, therefore, in case of economic crises, it is important to promptly take measures to improve the work of social protection institutions. As the analysis has shown, the economic crisis has led to an increase in the flow of consumers of social services due to a decrease in the population's income and an increase in the number of citizens who find themselves below the poverty line.

Religious organizations have a positive impact on social protection organizations, really helping the socially vulnerable groups of the population to cope with difficult life situations. 
Institutions such as health and education ones work closely with social protection organizations and with each other to achieve the common goals.

\section{Acknowledgements}

The reported study was funded by RFBR according to the research project №20-310-90018 «Conversion of the scientific potential of the region to solve the problems of global scientific and technological fronts».

\section{References}

1. A.F.Shakirova, Electronic Economic Bulletin of Tatarstan, 2, 46 (2014)

2. Collegium materials, Main results of the development of physical culture and sports in the Republic of Tatarstan in 2019 (2020)

3. M.R. Safiullin, L.A. Elshin, Yu.G. Mingazova, M.R. Zainullina, M.I. Prygunova, E.P. Demkina, Socio-economic situation of the Republic of Tatarstan: sustainability, trends, development prospects (2016)

4. Russian Public Opinion Research Center, Indices of social well-being (2020)

5. Levada Center, Economic crisis and consumption (2015)

6. L.B. Tomilina, Humanitarian of the South of Russia, 2, 214 (2018)

7. N. A. Mitrokhin, Russian Orthodox Church: current state and urgent problems (2006)

8. A.V.Makhiyanova, A.F. Shakirova, Social Sciences and Interdisciplinary Behavior Proceedings of the 4th International Congress on Interdisciplinary Behavior and Social Science, 135(2016)

9. E.I. Sigida, Theory and Methodology of the Practice of Medical and Social Work (2013)

10. D. M. da. Silva, Multidisciplinary Scientific Journal,5,39 (2017)

11. O.S. Stepanova. Sociodynamics, 1, 49(2019) 